\title{
Determination of the Artificial Filtering Massif Location for Purification Quarry Wastewaters of Kamyshansky Open Pit Mine
}

\author{
Maxim Tyulenev 1,*, Sergey Markov², Eugene Makridin ${ }^{3}$, Yury Lesin ${ }^{2}$, and Vyacheslav \\ Gogolin 4 \\ ${ }^{1}$ T.F. Gorbachev Kuzbass State Technical University, Open Pit Mining Department, 650000 \\ Kemerovo, 28 Vesennyaya st., Russian Federation \\ ${ }^{2}$ T.F. Gorbachev Kuzbass State Technical University, Surveying and Geology Department, 650000 \\ Kemerovo, 28 Vesennyaya st., Russian Federation \\ ${ }^{3}$ JSC «SUEK-Kuzbass», 652507 Leninsk-Kuznetsky, 1 Vasil'eva st., Russian Federation \\ ${ }^{4}$ T.F. Gorbachev Kuzbass State Technical University, Department of Mathematics, 650000 \\ Kemerovo, 28 Vesennyaya st., Russian Federation
}

\begin{abstract}
The most common purification methods in the coal industry are settling ponds and filtering treatment constructions. But in some cases, the use of traditional methods and schemes of water purification is complicated by the conditions of water discharge or does not provide the required water quality. For example, sharp seasonal fluctuations in the level of discharge and water pollution, a large number of spillways distant from each other and a change in their location during the development and moving of mining operations often make it difficult to use expensive and difficult to operate industrial wastewater treatment plants. Often, mining enterprises have a shortage of land areas to place such plants. In this regard, studies have been conducted aimed at identifying the possibility of water purification from suspended solids by filtering in arrays of coarse rock and semi-rock. Such arrays included, first of all, overburden dumps, various technological dams and embankments, as well as specially constructed filter arrays from mining waste. This article presents the results of studies to determine the location of the filter massif in the open pit "Kamyshansky".
\end{abstract}

\section{Introduction}

Seeing the constant growth of coal production in Kuzbass, the negative impact on the aquatic environment is also increasing due to the growth in the volumes of water discharged by mining enterprises. This effect, first of all, consists in chemical pollution of the surface waters of the hydrosphere with salts of heavy metals, organic substances (oil products), and also particles of coal and overburden rocks.

\footnotetext{
*Corresponding author: tma.geolog@kuzstu.ru
} 
The dynamics of the number of cases of extremely high pollution (EHP) and high pollution (HP) of the surface waters of the Russian Federation from 2007 to 2017 shows a relatively even weak uptrend without expressed annual fluctuations in the values of the total number of EHP and HP cases. At the same time, in the general case, EHP means the pollution level exceeding the maximum permissible concentrations (MPC) for substances of 1 and 2 of hazard class 5 or more times, for substances of class 3 and $4-50$ or more times; HP means the pollution level exceeding the MPC for substances of 1 and 2 of hazard class by 3-5 times, for substances of classes 3 and $4-10-50$ times, and for phenols, oil products, copper, manganese and iron ions - by 30-50 times.

\section{Materials and methods}

The number of perennial values of the indicators under consideration is conventionally divided into two periods: (a) an equable increase in the number of cases of EHP and HP from 2007 to 2009 and (b) a sinusoidal variation in the number of cases of EHP and HP with a period of 3-4 years from 2009 to 2017 . At the same time, the last three years have been a descending branch of a steady trend (Fig. 1).

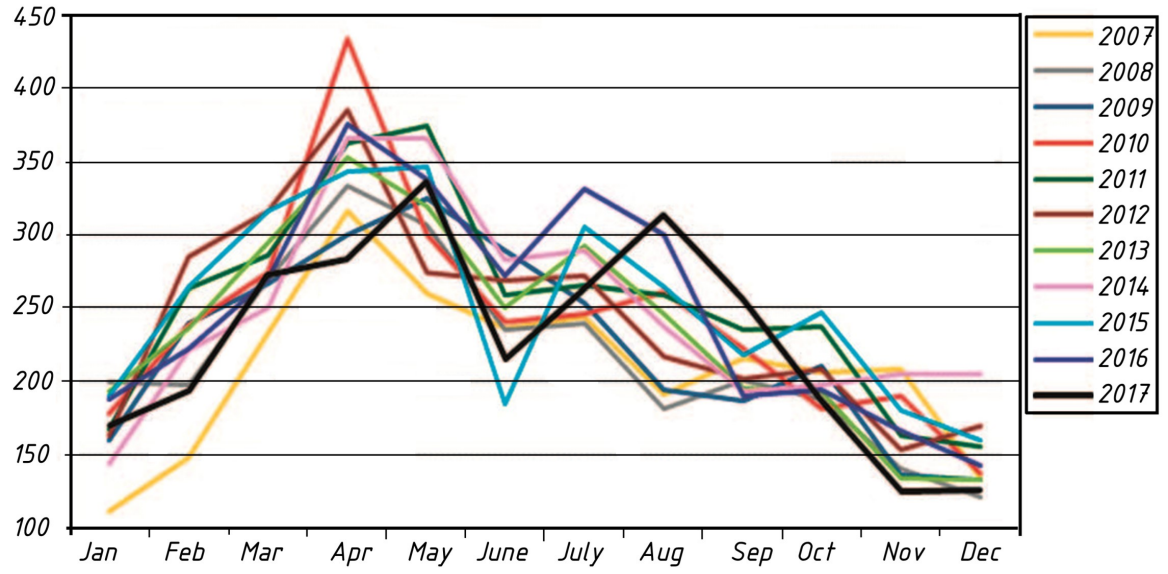

Fig. 1. Intra-annual distribution of the number of cases of HP and EHP of surface waters.

An analysis of the monthly distribution of the number of cases of HP and EHP for the period from 2007 to 2017 shows that their maximum values occur in April and May, which is explained by spring floods. Also, a local HP-EHP maximum is observed in July, which is associated with a decrease in surface runoff due to a relatively small amount of precipitation and, as a result, a relative increase in the concentration of pollutants. The data obtained are confirmed by earlier studies [1-8].

\section{Results}

It should be emphasized that a particular danger is associated with chemical pollution of the hydrosphere, which is a very mobile medium in which pollutants are able to spread over long distances. Since settling is applicable mainly for trapping particles larger than 100 microns and is not suitable for purifying water from fine suspensions and solutes, sequential purification is often used in the purification of quarry waters, often including such methods as:

- mechanical cleaning of coarse particles by settling in primary clarifiers; 
- coagulation of fine particles and solutions contained in the water after the first stage;

- filtering of pre-treated water through artificial filter dams;

- final settling and discharge to the nearest surface water bodies.

The most widely used in the primary treatment of pit water are methods of mechanical removing of coarse particles, i.e. clarification in a gravitational field or settling, as well as the filtering method in the artificial filtering massifs (AFM).

Water settling is carried out in ponds-clarifiers and different settlers - horizontal, inclined, radial, vertical and others. The most widely used clarifying ponds and horizontal sedimentation ponds (settlers). Using them as independent wastewater treatment plants in most cases does not provide for obtaining regulatory purified water. The cleaning effect for horizontal settlers is $9-88 \%$, and for settling ponds - 16-92\%. Filtration of pre-treated water in settling ponds through the AFM leads to additional wastewater treatment. This involves mainly two processes: mudding and adsorption.

The first process allows to mechanically hold particles of suspensions moving together with the water flow through the load in the pores between pieces of rock in the AFM.

The second process is used mostly for true or colloidal solutions of substances, causing their adsorption on the surface of the AFM pieces.

A significant number of works [7-17] are devoted to the study of natural sorbents and adsorption processes characteristic of phase separation surfaces. Natural sorbents for effective purification of industrial wastewater from dissolved and very fine (colloidal) mechanical particles can act overburden rocks of the developed deposit, with a high specific surface area. For the conditions of the Kuzbass, it can be highly fractured weathered sandstones and siltstones (including their carbonaceous species), also coal, diluted with overburden rocks to a substandard state. Very high filtration rates give the socalled burnt-out - burnt rocks.

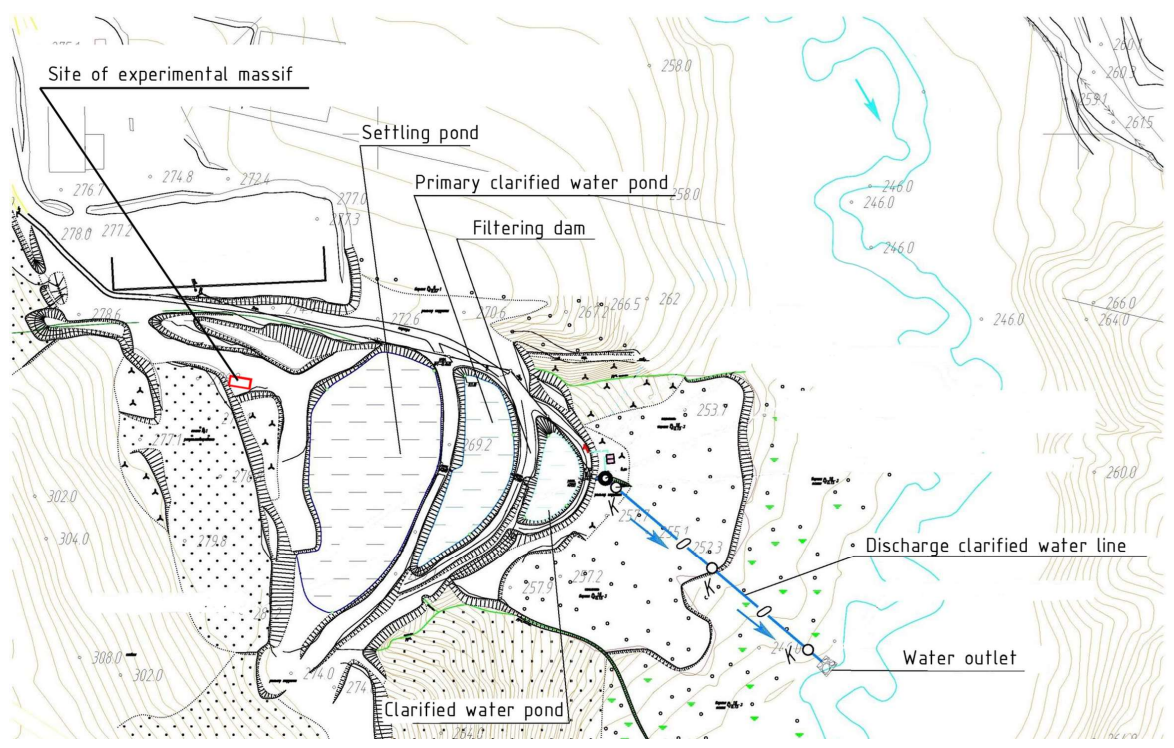

Fig. 2. Choosing the location of the AFM.

The foregoing allows us to conclude that, taking into account modern requirements for the quality of treated water, it is necessary to develop a technology for the purification of open pit wastewater, which ensures purification to discharge standards. In addition, this technology should be low-cost to ensure its widespread use. 
To carry out experimental work on the development of measures for the treatment of quarry wastewater in the AFM of overburden rocks, it is proposed to create an experimental AFM in the place indicated in Fig. 2.

\section{Conclusions}

The specified location is most appropriate for the AFM location for the following reasons: 1. Proximity to the primary settling pond of the existing treatment facilities: there is no need to build additional facilities to collect and discharge purified water to the AFM, since it is possible to discharge it into the settling pond of the existing treatment facilities.

2. The relative proximity to the point of pit water in existing treatment facilities: there is no need to install additional pipelines to supply wastewater to the experienced AFM, which significantly reduces the cost of research. In this case, the flow of wastewater can be carried out using portable pumps and temporary flexible pipelines (sleeves) from the existing discharge point, located at a distance of about 20-30 m from the constructed AFM.

3. Transport accessibility: the existing road with the adjacent territory will allow the creation of a ditch under the AFM directly on the ground; facilitates the production of loading AFM by overburden rock from dump trucks without cutting additional transport communications and unloading platforms.

4. Power supply: a mobile substation located nearby (providing power supply to pumps for filling tank trucks with water for their own needs) makes it possible to connect an additional pump for pumping wastewater into the AFM.

\section{References}

1. L. Lei, L. Jian, W. Yutao, W. Nvjie, and W. Renqing, International Journal of Environmental Research, 5(3), 787-796 (2011)

2. T. Areepitak, J. Ren, Environmental Science and Technology, 45(13), 5614-5621 (2011)

3. S.L. Arnon, P. Marx, K.E. Searcy, A. Packman, Hydrological Processes, 24, 108-114 (2010)

4. V.Yu. Bazhin, V.B. Kuskov, Ya.V. Kuskova, Ugol', 4, 50-54 (2019)

5. T. Esakkimuthu, D. Sivakumar, S. Akila, Pollution Research, 33(3), 567-571 (2014)

6. S.K. Gupta, K.S. Ramesh, Shaik Sameer, Pollution Research, 34(1), 111-120 (2015)

7. J.I. Jones, J.F. Murphy, A.L. Collins, D.A. Sear, P.S. Naden, P.D. Armitage, Applying Research, 9, 67-73 (2011)

8. V.A. Gogolin, Yu. V. Lesin, Journal of Mining and Geotechnical Research, 3, 42-55 (2018)

9. D.L. Karwan, J.E. Saiers, Water Resources Research, 48, 15-19 (2012)

10. I.A. Mironenko, S.I. Protasov, Journal of mining and geotechnical engineering, 4, 24-34 (2019)

11. M.M. Sharma, Y.C. Yortsos Y.C. AIChE Journal, 33, 1636-1643 (1987)

12. S. Xu, B. Gao, J.E. Saiers, Water Resources Research, 42, 12-16 (2006)

13. D.L. Karwan, J.A. Gravelle, J.A. Hubbart, Forest Resources, 53(2), 181-188 (2007)

14. A. Zamani, B. Maini, Journal of Petroleum Science \& Engineering, 69, 71-88 (2009)

15. Zheng Xi-lai et al., Journal of Hydrology, 511, 199-204 (2014) 
16. A.B. Palamarchuk, A.V. Stukan, T.N. Gvozdkova, Journal of mining and geotechnical engineering, 4, 50-68 (2019)

17. N. Nedjah, A. Mizi, D. Daas, N. Laskri, M. Baccouche, Pollution Research, 35(2), 229-234 (2016) 